\title{
Tannin-Ca Complex as Green Thermal Stabilizer Additive for PVC: Viscoelastic Properties
}

\author{
Hussein A. Shnawa ${ }^{1}$, Yousef Jahani ${ }^{2}$, Moayad N. Khalaf ${ }^{1}$, Abed Alamer H. Taobi ${ }^{1}$ \\ ${ }^{1}$ Chemistry Department, College of Science, University of Bsarh, Basrah, Iraq \\ ${ }^{2}$ Department of Plastics, Faculty of Processing, Iran Polymer and Petrochemical Institute, Tehran, Iran \\ Email: ${ }^{*}$ Hussanqi@yahoo.com
}

Received 25 March 2015; accepted 15 May 2015; published 18 May 2015

Copyright (C) 2015 by authors and Scientific Research Publishing Inc.

This work is licensed under the Creative Commons Attribution International License (CC BY). http://creativecommons.org/licenses/by/4.0/

\section{Abstract}

This study investigated the viscoelastic and rheometeric properties of PVC stabilized with tanninCa complex as totally bio-based thermal stabilizer. Dynamic mechanical thermal analysis (DMTA) used to characterize the viscoelastic properties of PVC samples obtained by thermal mixing of PVC with three composition percentages $(1.0,2.0$, and 3.0) part per hundred ratios (phr) of tannin-Ca complex with this polymer. The torque rheometery test used to monitor the effect of tannins derivative on the thermal stability and mixing properties of PVC formulations during samples processing. For that purpose, PVC sample with 2 phr commercial thermal stabilizer (Reapak B-NT/ 7060) was used for comparison and considered as reference samples. Before the glass transition temperature of PVC at $30^{\circ} \mathrm{C}-60^{\circ} \mathrm{C}$, the DMTA curves show that the values of storage modulus and tan delta of PVC samples stabilized with tannin derivative were very similar with those of PVC sample stabilized with commercial thermal stabilizer. The glass transition temperature $(\mathrm{Tg})$ of PVC stabilized with commercial thermal stabilizer and with tannin-Ca complex occurred at about $76^{\circ} \mathrm{C}$. In a sequence, after the glass transition region of PVC samples, the DMTA scans confirmed that the PVC samples with 2 phr tannin-Ca complex have relatively longer flowing stage which occurs at lower temperatures by $18^{\circ} \mathrm{C}$ per that of PVC sample stabilized with commercial stabilizer. Global results of the torque rheometery which have suitable plateau stages and the DMTA show that the processing thermal stability and thermal flexibility of PVC are clearly increased with the incorporation of tannin-Ca complex. All the PVC formulations with tannins-Ca complex show excellent viscoelastic properties which were found to be slightly best or much closed to those obtained for PVC stabilized with commercial thermal stabilization.

\section{Keywords}

PVC, Viscoelastic Properties, Tannin-Ca Complex, Thermal Stability, Tg

\footnotetext{
"Corresponding author.

How to cite this paper: Shnawa, H.A., Jahani, Y., Khalaf, M.N. and Taobi, A.A.H. (2015) Tannin-Ca Complex as Green Thermal Stabilizer Additive for PVC: Viscoelastic Properties. Open Journal of Organic Polymer Materials, 5, 69-78. 


\section{Introduction}

Polyvinyl chloride, PVC is one of the main components of modern commodity thermoplastic polymers used for various applications. As examples of PVC applications, it is used in building and constructions, packaging, electrical, automotive and furniture/office equipment, clothing, foot wears, and so on. PVC can be manufactured in a range of flexibilities and rigidities. Also, it can be used in a wide range of temperatures, and it retains its strength and durability at low temperatures. In addition, PVC formulations exhibit excellent strength and toughness, exhibit very good water, fire and chemical resistance and stability, and are also biocompatible for some applications. Following this, PVC is relatively lower cost and high-performance value and it has safety and cost advantages for a wide variety of medical applications, especially for single-use disposable devices [1] [2].

In an opposing view, PVC is characterized by poor heat and UV resistance due to the presence of some abnormal structures (weak sites) that originate from polymerizations process. Addition of thermal stabilizers is, therefore, required to prevent thermal degradation during process. The poor thermal stability of PVC leads to an extensive discoloration of the polymer and deterioration of its physical and mechanical properties. Because all these changes are accompanied by deterioration on some of the useful properties of the polymer, it has become the practice to process PVC in the presence of this type of PVC additives, namely heat stabilizers [3] [4].

Nowadays, in the polymer additives or other fields, there is an increasing demand for natural-based products in industrial and consumption applications, due to environmental issues and the depletion of non-renewable raw materials. Renewable resources can constitute an attractive alternative to conventional petrochemical resources [5] [6]. Thus, tannins in one example to the natural phenolic products are used in many investigations as raw material for synthesis and developments of some products such as bio-based epoxy resins [7], environmentalfriendly rigid foams [8], and low-formaldehyde emission adhesives [9].

Natural polyphenolic materials, in the same manner, such as flavonoids and condensed tannins extracted from plant materials (or from forestry or viticulture by-products) are available relativity in high quantities. They have been historically used in the leather tanning and adhesives industries. Condensed tannins, Figure 1(a), primarily, are polyphenolic oligomers based on flavanyl repeat units with the hydroxylation pattern providing potent antioxidant activity [10] and for some metal ions chelating ability [11] (Figure 1(b) [12]).

In plants, these compounds offer a range of protective roles, including astringency, pathogen, and UV inhibition. From the chemical point of view, it is difficult to define the tannins since the term includes some miscellaneous monomers, oligomers and polymers and its isomers with molecular weight reach to 20,000 Da or more. It may be said that the tannins are complex mixture of phenolic compounds at different molecular weights with the ability to form reversible and irreversible complexes mainly with proteins, and to lesser extent with polysaccharides and mineral ions [13] [14].<smiles>Cc1cc(O)c2c(c1C1c3c(O)cc(O)cc3OC(c3cc(O)c(O)c(C(=O)O)c3)C1O)OC(c1ccc(O)c(O)c1)C(O)C2C(=O)O</smiles>

(a)<smiles>Oc1cc(O)c2c(c1)OC(c1cc(O)c3c(c1)O[CH]O3)C(O)C2c1c(O)cc(O)c2c1OC(c1ccc3c(c1)O[CH]O3)C(O)C2O</smiles>

(b)

Figure 1. Chemical structures of condensed tannins (a); and of tannin-Ca complex (b). 
Analogous to other pant phenols, tannins are among the array of chemical compounds that are widely distributed in the plant kingdom and belong to the phenolic class of secondary plant metabolites, with oligomeric and polymeric compounds having multiple structure units with free phenolic groups [14].

The study of M. D. Samper et al. [15] presents using natural phenolic compounds derived from flavonoids type such as chrysin, quercetin, silibinin and other in the stabilization of polypropylene against thermo-oxidation degradation and UV radiation. Global results of this study show that flavonoid compounds of type flavonols (quercetin and silibinin) provide the best results in stabilizing both against oxidation and against the action of UV radiation. Warren J. Grigsby et al. [16] synthesized tannin hexanoate and tannin hexanoate acetate. Esterified and native condensed tannins have been evaluated in polypropylene and in the commercial aliphatic polyester type (Bionolle), while the presence of tannin additives contributes color to the plastics; by this study, the author reported that the presence of these materials can provide beneficial functionality to the plastics such as antioxidant activity and UV stabilization. The present study was directed to study the effect of tannins based thermal stabilizer on the viscoelastic properties (DMTA) of PVC. Tannin-Ca complex was synthesized and characterized by our previous study [12].

The dynamic mechanical technique involving application of a sinusoidal oscillating stress to a material and the analysis of the resultant strain is now widely practiced as a polymer characterization technique [17] [18].

The stabilizing efficiency of tannin-Ca complex and its effect on the PVC properties were compared to those of a commonly used synthetic $\mathrm{Ca} / \mathrm{Zn}$ thermal stabilizer. For these goals, two main questions were studied: 1) the effect of the tannin derivative on the processing stability of PVC; 2) polymer characteristics in term of DMTA parameters in the presence of tannin-Ca complex after thermal mixing and compression molding.

\section{Materials and Methods}

\subsection{Materials}

Suspension grade of PVC with (k-value 65) type S6558 was supplied from Bandar Imam Petrochemical Co. (Iran). Tannins used in this study was isolated from eucalyptus outer bark by aqueous sodium hydroxide solution $2 \%$ per dry weight of the bark. Sodium hydroxide, Calcium hydroxide and $\mathrm{HCl}$ were purchased from Fluka; DOP was provided from Farabi petrochemical industries (Iran). Reapak B-NT/7060, commercial thermal stabilizer type (Ca/Zn-based powder under) was supplied by Reagens Co. (Italy).

\subsection{Methods}

\subsubsection{Preparation of Tannin-Calcium Complex [12]}

$10 \mathrm{~g}$ of tannins powder were dissolved in $100 \mathrm{ml}$ distillation water at $60^{\circ} \mathrm{C}$ with continuous stirrer. The pure and filtrated of the saturation aqueous solutions of $\mathrm{Ca}(\mathrm{OH})_{2}$ was added gradually to the tannin solution with continuous mixing by magnetic stirrer, the addition process continuous until the $\mathrm{pH}$ was raised to 12 . After that, the mixture was allowed to stand up for 24 hours. Brown and thick precipitate was obtained which was filtered, then washed with excess of distillation water to $\mathrm{pH}$ about 6 and dried for 24 at $60^{\circ} \mathrm{C}$.

\subsubsection{Samples Preparation}

The samples were prepared by mixing the constituents according to the composition percentages (by phr of tannins-Ca complex) in a Brabender internal mixer, Lab. Station-Plasti-Corder, W50-2002, Germany, equipped with Cam blades at $165^{\circ} \mathrm{C}$ and $80 \mathrm{rpm}$ until leveling off the torque curve for 4 minutes. The compounded PVC with appropriate amounts tannin-Ca complex and with $10 \mathrm{phr}$ DOP in all formulations were compression molded by Toyseiki Mini press, Japan, at $200^{\circ} \mathrm{C}$ for $10 \mathrm{~min}$ into $1.5 \mathrm{~mm}$ thickness sheets. After the period of compression molding, the samples sheets were cooled to room temperature then de-molded. These sheets are used to prepare specimens for DMTA tests.

\subsubsection{Dynamic Mechanical Thermal Analysis (DMTA)}

The viscoelastic properties of samples were determined by using a Triton DMA, TriTec 2000 (England), in single cantilever bending mode. The Rectangle samples (30 $\mathrm{mm} \times 10 \mathrm{~mm}$ with $1.5 \mathrm{~mm}$ thickness) were tested at a frequency of $1 \mathrm{~Hz}$, from $25^{\circ} \mathrm{C}$ to $200^{\circ} \mathrm{C}$ with $4^{\circ} \mathrm{C} /$ min heating rate. 


\section{Results and Discussion}

Practically, thermal stabilizers play a key role in the PVC formulations and processing. Without these materials, PVC cannot be acceptable to transfer from native polymer to useful final products. During processing of PVC, as other thermoplastic polymers, stability against thermo-oxidative stress plays an important task. It determines, among others, the maximum residence time within the production machine. Therefore, conditioning of polymers with stabilizers is of decisive importance for the production process.

The principle of torque vs. time measuring is based on making visible of the resistance the sample material opposes to the rotating blades. Torque curves during the course of thermal mixing (4 min) of PVC with these additives were illustrated in Figure 2. This diagram shows the relationship between torque (melt polymer viscosity) and temperature/time in consideration of structural changes of the material. Thus, during all mixing period the curves into Figure 2 show that there are no significant rise (or decreasing) in the torque values after plateau region and continues at this minimum value which so-called Stable Point (St) [19].

This experimental evidence for the high stabilizing efficiency of tannin-Ca complex as processing thermal stabilizer. This point suggests that the tannin-Ca complex will provide more process stability for PVC. The torque measurements also have been successful in obtaining qualitative information concerning relative to melt viscosity and mixing processes of the polymers with different additives. The parameter obtained describe the fundamental behavior of this materials [20] [21]. Thus the brabender PolyLab System internal mixer offers a quick and reliable method of examining the performance of these materials.

The torque/time curves of PVC samples present the relationship between the values of torque during the mixing time of PVC with the commercial thermal stabilizer at ( $2 \mathrm{phr}$ ) and with tannin-Ca complex that used in this study, at (1, 2, and 3) phr. It distinctly expressed thermo-mechanical mixings as well as thermal stability of PVC

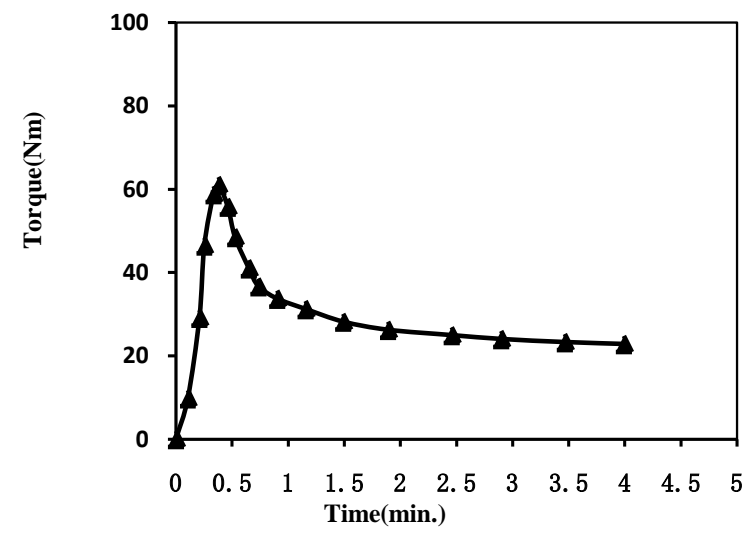

(a)

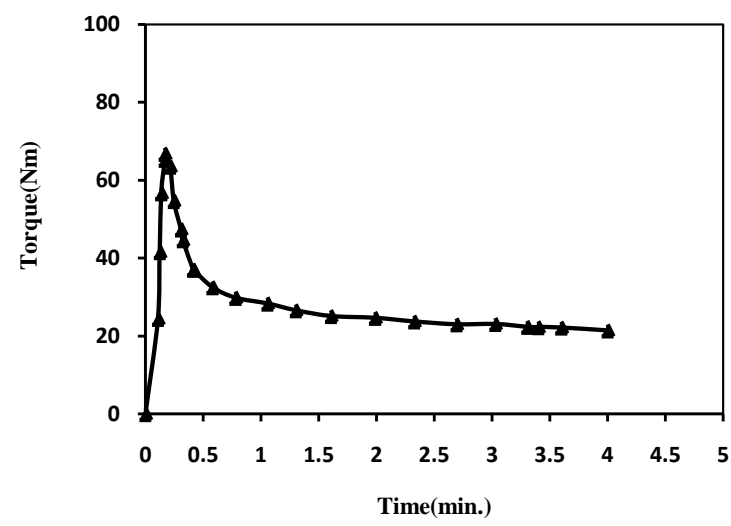

(c)

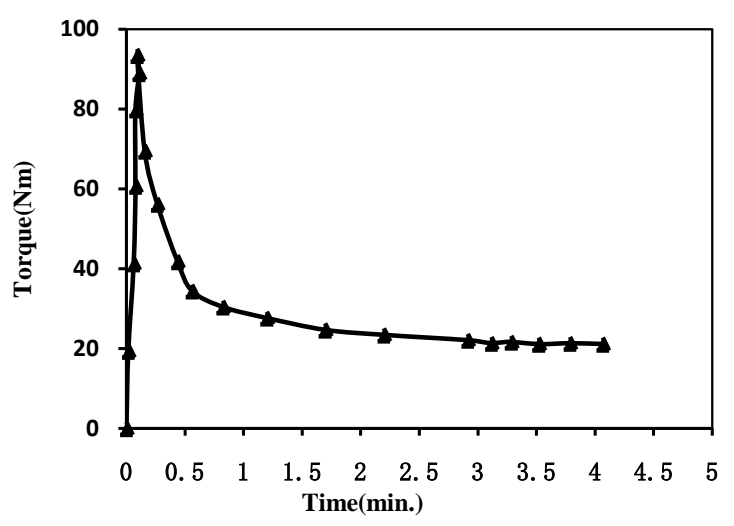

(b)

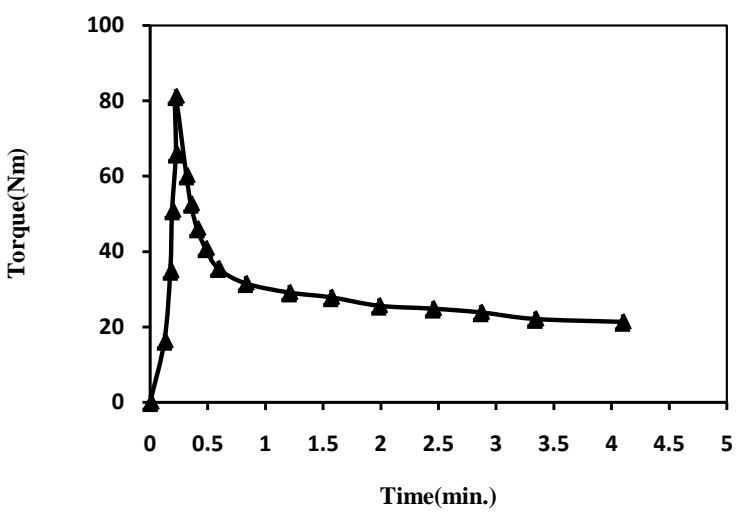

(d)

Figure 2. Torque (Nm) curves for PVC stabilized with 2 phr com. therm. stab. (a); with 1 phr tannin-Ca complex (b); with 2 phr tannin-Ca complex (c); and with 3 phr tannin-Ca complex (d). 
during mixing process based on the shear viscosity. During the first minute, the curve shows the first torque peak or loading peak which represents the intensities of torque depicted values (peaks) simultaneously, of material loaded into the chamber of mixer system.

After the start time of mixing process, the sample is now distributed in the hot mixer chamber and the polymer become soft. Because of this, the torques gradually drops until slightly stable at ground value. This behavior can be observed in both PVC stabilized with commercial thermal stabilizer and with tannin derivative. TanninCa complex added to the PVC polymer have the task to catch chlorine ions (and/or $\mathrm{HCl}$ ) which were separated from the polymer chains. It has a certain capacity to bind those chlorine ions and not allows to HCl to work as auto catalyst for more degradation. Therefore, the tannin derivative makes this polymer more thermal resistance [12].

The degradation process included of secondary reactions such as crosslinking reactions and other types, all these reactions caused significant changes in the torque curve. The crosslinking reaction directly lead to increased the torque values of polymer melt, the rise point in the torque curve considered as indicator to these reactions and as point to the degradation process in polymer system. Thus, during all mixing period (4 min) there are no significant rise (or decreasing) in the torque values and continues at this minimum value which socalled Stable Point (St), which suggests that the PVC processing in the presences with tannin-Ca complex will provide excellent process stability.

In the PVC case, longer plateau and time indicate to sample which is more thermal stability that in it turn correspond to higher capability thermal stabilizer. One can clearly see that the PVC sample with tannin-Ca complex content of $2.0 \mathrm{phr}$ has a long stable time as that of commercial thermal stabilizer. The graph also shows, that the difference percentage of this additive had influence on the thermal stability and so on the melt viscosity of the PVC. This has significantly been meaning for controlling the viscosity and thermal stability of polymer during mixing time.

Figure 2(b) shows that the PVC stabilized with 1 phr tannin-Ca complex. This sample exhibit a similar melt torque curve after polymer fusion. However all PVC with three tannin-Ca complex compositions samples after fusion, dos not exhibit a slope. The absence the rabid increasing or decreasing in the torque curves of PVC samples after fusion suggests that the tannin derivative will proved more process stability for a long the mixing times. For this time (4 min) there are on detectable any rise in the torque curves. Again this behavior can be attributed to more stable melt torque of PVC is exhibited by the tannin derivative.

In addition to above discussion, dynamic mechanical thermal analysis, DMTA is an extremely versatile and sensitive method that enables the complete scan of relaxation mechanisms in viscoelastic materials. Dynamic mechanical testing is considered the most sensitive method for measuring the glass transition and secondary transitions of polymers. Accurate solid state measurements of the material's glass transition temperature $\mathrm{Tg}$, modulus $\left(E^{\prime}\right)$ and damping $(\tan \delta$ ) are used to predict practical use temperatures, impact properties, energy dissipation, stiffness and many other performance properties [22] [23].

Figures 3-6 illustrated the viscoelastic properties of PVC in the presence of tannin-Ca complex. DMTA curves reflect the influence of thermal history of PVC samples and can be used as indirect indicator to the normality of polymer structure. So, it can be used as a mean to realize the stability during thermal mixing and molding. Specifically, in the temperatures range $30^{\circ} \mathrm{C}-100^{\circ} \mathrm{C}$, chemical reactions that may occur into PVC are very limited and can be ignored. Therefore, only the physical events, in particular, glass transition temperature can be seen which consist of a change in heat capacity during the transition from glassy to rubbery states. Hence, it can be conclude according to the shape and data of DMTA curves that the physical properties of PVC have affected in very limited extent by tannin-Ca complex at concentration levels used in this study before the $\mathrm{Tg}$.

By Figure 3 and Figure 4, it can be clearly recognized the differences as well as the similarity in the position and properties of thermal transitions for PVC stabilized with 2 phr commercial stabilizer, and for PVC stabilized with 2 phr tannin-Ca complex. By contrast, for all PVC/tannin-Ca complex samples, DMTA curves show the main thermal transitions and thermal relaxations during the temperature range between $25^{\circ} \mathrm{C}-200^{\circ} \mathrm{C}$.

Therefore, the result of comparison the DMTA values such as $\mathrm{Tg}$, storage and elastic modulus, $\tan \delta$ of PVC stabilized with commercial stabilizer and PVC stabilized with tannin-Ca complex give direct information about the properties of the polymer after any thermal processing and about the efficiency of the thermal stabilizer. In the state of PVC, as discussed earlier, introduction of the thermal stabilizer (and other type of additives i.e. antioxidants) into the polymer system greatly increased the polymer resistance to thermal conditions and as a result the mobility, the softening, and the thermal transfer of the polymer chain will stay at very limited changes, and 


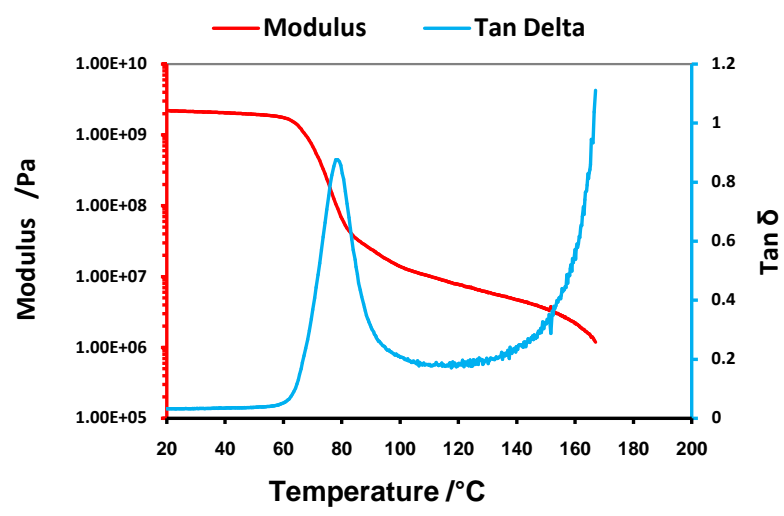

Figure 3. DMTA scans of PVC stabilized with 2 phr commercial thermal stabilizer.

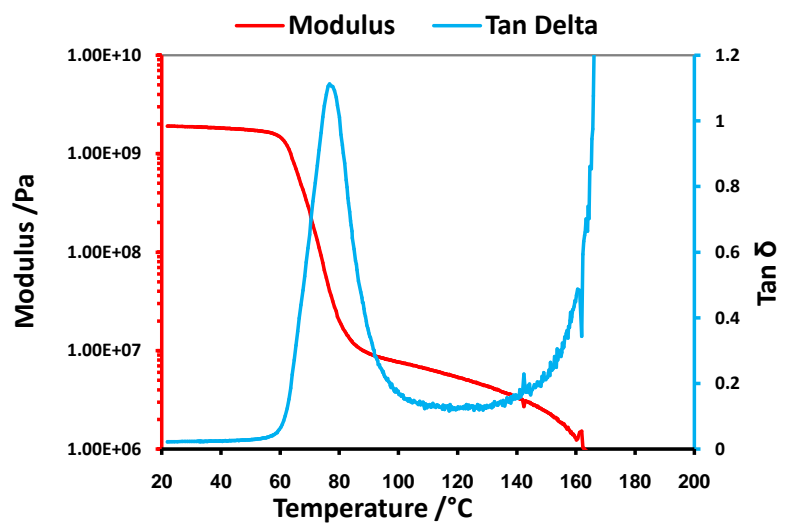

Figure 4. DMTA scans of PVC stabilized with 2 phr tannins-Ca complex.

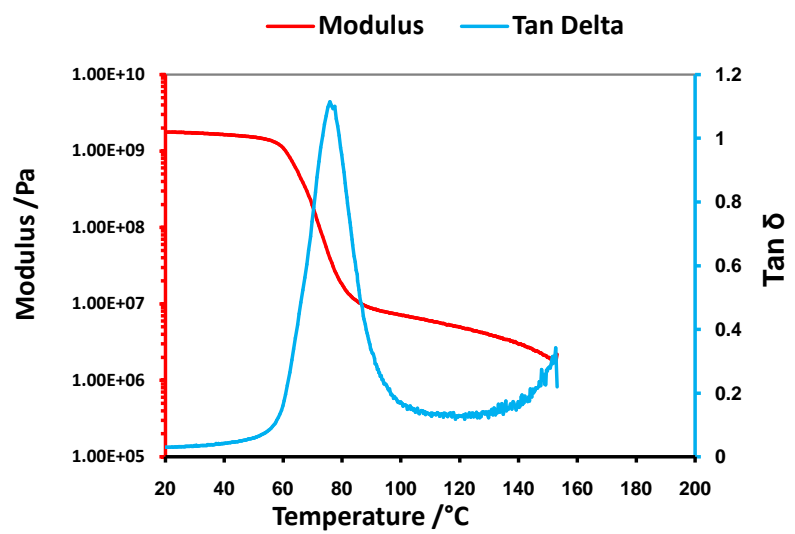

Figure 5. DMTA scans of PVC stabilized with 1 phr tanninsCa complex.

this subsequently reflect the structure of the polymer [22] [23].

The dynamical mechanical data of the PVC samples are shown in Table 1 . The data in Table 1 show the ranges of similarity between the properties of PVC stabilized both with commercial thermal stabilizer and with tannin derivative. As example, the $\mathrm{Tg}$ of PVC for all samples are ranged between $75.9^{\circ} \mathrm{C}-76.8^{\circ} \mathrm{C}$, Figures 4-6. According to $\mathrm{Tg}$ values of PVC stabilized with tannin derivative, it can be concluded the effect of this derivative in protection this polymer during thermal mixing. As shown by Figures 4-6, and before glass transition region, 


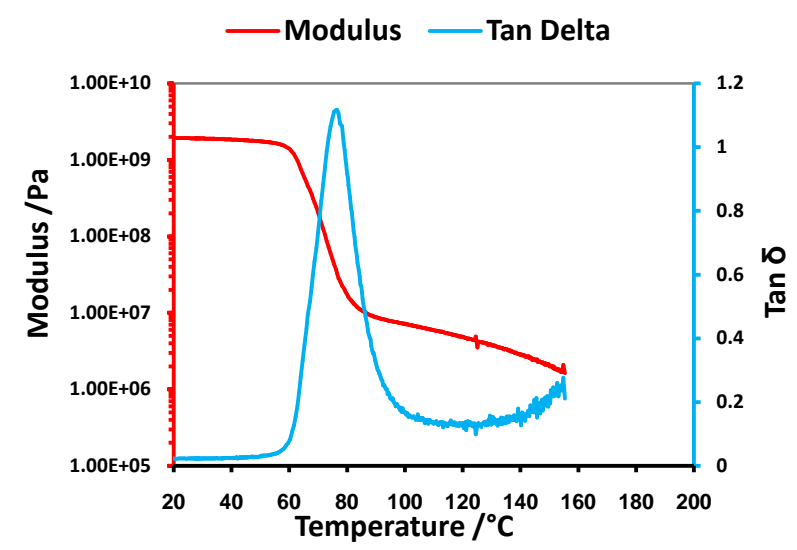

Figure 6. DMTA scans of PVC stabilized with 3.0 phr tannins-Ca complex.

Table 1. DMTA data (storage modulus and tan delta) and Tg of PVC samples.

\begin{tabular}{|c|c|c|c|c|c|c|c|c|c|}
\hline \multirow{2}{*}{ Samples } & \multicolumn{3}{|c|}{ Storage modulus $(\mathrm{Pa})$} & \multicolumn{3}{|c|}{ Tan delta } & \multirow{2}{*}{$\operatorname{Tg}^{*}\left({ }^{\circ} \mathrm{C}\right)$} & \multirow{2}{*}{ Modulus at $T g$} & \multirow{2}{*}{ Tan delta at $T g$} \\
\hline & $30^{\circ} \mathrm{C}$ & $70^{\circ} \mathrm{C}$ & $140^{\circ} \mathrm{C}$ & $30^{\circ} \mathrm{C}$ & $70^{\circ} \mathrm{C}$ & $140^{\circ} \mathrm{C}$ & & & \\
\hline PVC/2 phr com. therm. stab. & $1.70 \mathrm{E} 09$ & 1.67E08 & 3.25E06 & 0.024 & 0.074 & 0.142 & 76.2 & $3.68 \mathrm{E} 7$ & 1.005 \\
\hline PVC/1 phr tannin-Ca complex & $1.716 \mathrm{E} 09$ & 1.97E08 & $3.00 \mathrm{E} 06$ & 0.033 & 0.737 & 0.173 & 75.9 & $3.95 \mathrm{E} 07$ & 1.115 \\
\hline PVC/2 phr tannin-Ca complex & $1.88 \mathrm{E} 09$ & $2.60 \mathrm{E} 08$ & 3.324E6 & 0.0236 & 0.653 & 0.154 & 76.8 & 4.04E07 & 1.113 \\
\hline PVC/3 phr tannin-Ca complex & 1.90E9 & 2.06E08 & 2.88E6 & 0.0223 & 0.731 & 0.127 & 76.1 & 4.312E07 & 1.112 \\
\hline
\end{tabular}

${ }^{*} \mathrm{Tg}$ was determined by the peak of tan delta.

the storage modulus (E') of the three different PVC/tannin-Ca complex compositions are about 1.95E+9Pa. All these values appear a very closed to that of PVC stabilized with commercial stabilizer, Figure 3.

This result clearly indicate that thermo-plastic properties of PVC influenced by the presence of tannin derivative which works to prevent or reduce the thermal degradation and undesirable changes in the chemical structure of polymer during thermal mixing and thermal compression molding courses such as cross linking reactions. One of the main reasons for increased the $T g$ values (or $T g$ range) in a polymer, is the crosslinking reactions. These reactions restrict the movement of polymer segments and lead to rapid increasing in the molecular weight of polymer which will result in an increase of the $T g$ or to $T g$ appears at higher temperatures ranges. Based on the DMTA analysis results, the presence of tannin derivative actually reduce the formation of conjugated double bonds which are a result to dehydrochlorinations reactions of PVC and then prevent the crosslinking reaction during mixing or formulations process. In particular, the improvement of dynamic mechanical properties of PVC by tannin derivative can be explained in term of do not restricted the thermal motions and transitions of PVC chains such as $T g$ and flow transitions.

Indeed, the effect of tannin-Ca complex on dynamic mechanical thermal properties of the PVC revealed the PVC $T g$ temperature to range between $76^{\circ} \mathrm{C}-77^{\circ} \mathrm{C}$ as represented in Table 1 . Across this temperature range PVC with tannin-Ca additives showed limited changes in $T g$ in contrast to its value of PVC stabilized with commercial stabilizer and in the presence of $10 \mathrm{phr}$ DOP. Comparing the samples containing the same amount of thermal stabilizer, each PVC-tannin based system showed a $\mathrm{Tg}$ value of about $0.6^{\circ} \mathrm{C}$ higher than the corresponding PVC sample, this clearly show that the tannin-Ca complex had very limited influenced on $\mathrm{Tg}$ and have stabilization action as commercial thermal stabilizer, as well.

For all PVC samples, the loss modulus is relatively high with fairly steady state and have stable behavior around $(1.85 \mathrm{E}+09 \mathrm{~Pa})$ during the temperature from $30^{\circ} \mathrm{C}$ to $60^{\circ} \mathrm{C}$ until $\mathrm{Tg}$. With increase the temperature, as seen, the modulus drops rapidly (down to about 2.0E08Pa), Table 1 . As the temperature increases from $60^{\circ} \mathrm{C}$ to $80^{\circ} \mathrm{C}$, the main relaxation, which occurs after $60^{\circ} \mathrm{C}$ is attributed to the $T g$ of (10 phr plasticized) PVC which appears as sharp drop in the modulus curves, Figure 3. 
It is well known, that in glass transition region the polymer sample becomes less hard as storage modulus decreases and tan delta peaks. Tan delta peak height is typically between 0.1 and 1.2 . The onset can be taken as the $\mathrm{Tg}$. In leathery region the sample is tough but flexible. Side groups and cooperative segmental motion of the backbone occurs. Tan delta is below 1.0 this is slightly above the $T g$. Since here (in the $\mathrm{Tg}$ region) the polymer chains obtain more segmental mobility and their state changes from glassy (relatively hard) to rubbery (relatively soft) state by thermal induced [24] [25].

As shown in Table 1, before the glass transition region, the storage modulus (E)' of the three different PVC /tannin-Ca concentration levels, all the ( $\left.E^{\prime}\right)$ values are comparable to that of PVC/commercial stabilizer sample. Following this, after the glass transition region, in Figure 3, it appears that the samples transfer to the next relaxation region, namely, rubbery plateau region which is characterized by physical entanglement of the PVC chains and it in turn is reflection to relativity high molecular weight and homogenous chemical structure of PVC stabilized with tannin derivative comparison with that stabilized by commercial stabilizer.

Additionally, these transitions are also observed in the damping factor (tan delta) curves, Figures 3-6. As the temperature increases, the damping goes through a maximum in the transition region and a decrease in the rubbery region [25]. Whereas the samples with commercial thermal stabilizer have rubbery plateau and flowing stage start at about $100^{\circ} \mathrm{C}$, and at about $160^{\circ} \mathrm{C}$, respectively. For PVC with 2 phr tannin-Ca complex this stages start at $90^{\circ} \mathrm{C}$ and at $140^{\circ} \mathrm{C}$, respectively. In this stage the PVC polymeric chains mobility occurs and the polymer matrix become more soft and appears as melt.

As a matter of fact, in the fluid region, sample is flowing, water like and free chains movement and inter chains slipping occurs. Therefore, tan delta is much higher than 1.0. This is above the Tm in crystalline materials. Often treated as part of viscous region. PVC sample with commercial stabilizer and 10 phr plasticizer (DOP), Figure 3, and the samples with 2 phr tannin-Ca complex, Figure 4, have flow stages at temperature range $140^{\circ} \mathrm{C}$ - $160^{\circ} \mathrm{C}$. In fluid region free chain movement and inter chain slipping occurs. Once again, the flowing temperatures of PVC with tannin derivative are lower than that of PVC stabilized with commercial stabilized. Moreover, the Figure 4 shows that the length of this stage are longer than that of PVC/commercial stabilizer, this behavior can be attributed to more thermo flexible and thermo softening properties for PVC by effect of tannin-Ca complex as thermal stabilizer.

Generally, the value of the $\mathrm{Tg}$, length of rubber plateau, flowing stage and other physical properties can be used to monitor any changes in polymers structures and in the molecular weight. In this case, thermal degradation or cross linking by thermal treatment or thermal aging and they are indications to more thermal stabile of PVC structure. In the viscous region the sample is flows, fluids as temperature increases. Large scale main chain mobility occurs. In this rubber-elastic region, the polymer chains have full mobility and the properties are determined by the entangled network. Furthermore, the heat energy in flowing stages can caused physical as well as chemical effects on PVC, which also reflects the thermal history of sample and then the thermal stability of PVC during the thermal mixing and compression molding. Hence at it is observed, the effect of tannin-Ca complex can be seen also, in this stages. Whereas the samples that contain $1 \mathrm{phr}$ and $3 \mathrm{phr}$ tannin-Ca complex were founded to has longer flowing stage started at $150^{\circ} \mathrm{C}$ or below. With respect to sample without tannin derivative, this effect can attributed to samples with more softening and flowing behaviorsas result to the higher thermal stability in the presence of tannin-Ca complex.

On the whole, the DMTA study shows that the properties of PVC with presence of tannin-Ca complex do better (or not differ) from that of PVC with commercial thermal stabilizer. And then, the values $\mathrm{Tg}$ and other viscoelastic properties indicate directly to PVC samples with relativity high thermal stability and more chain flexibility caused by action of tannin-Ca complex. Hence, the presence of this derivative caused decreased or inhibition to any significant changes in the chemical structure or in its molecular weight during all the thermal treatment and thermal conditions for make PVC formulations. This can be explained by the stabilization effect of tannin derivative for PVC.

\section{Conclusion}

The thermal properties of PVC containing tannin-Ca complex in the absence of commercial thermal stabilizer were investigated in this study; generally, all the results indicate that the tannin-Ca can clearly improve the thermal stability and viscoelastic properties of PVC; this is mainly due to the action of tannin derivative as $\mathrm{HCl}$ trap and as antioxidants. According to the results of DMTA, it was showed that the tannin-Ca complex could 
impart addition stability and melt flexibility to the PVC compound. Torque Rherometry experimental results confirmed that the tannin-Ca complex increases PVC thermal stabilization against thermal-oxidation degradation, compared to the commercial stabilizer. Also, the results of this study point out that the tannin-Ca complex is an efficient stabilizer for PVC, even though in a lower extent (1 phr). Thus, it is possible to recommend the use of this bio-based additive as thermal stabilizer for PVC.

\section{Acknowledgements}

The authors gratefully acknowledge Dr. M. Nekomenesh director of Iran Polymer and Petrochemical institute (IPPI) and Dr. G. Naderi the head of international office in this institute for their large support and assistance during the period of carried out of the analysis. The authors also express their deep appreciation to Eng. G. H. Asghari, to Eng. H. Hosseini and to Eng. H. Hasani for their help during samples preparation and to the all analysis laboratory technicians of this institute for their helps and for providing the ultimate analysis results.

\section{References}

[1] McKeen, L.W. (2014) Plastics Used in Medical Devices, Ch. 3. In: Ebnesajjad, S. and Modjarrad, K., Eds., Handbook of Polymer Applications in Medicine and Medical Devices, Elsevier Inc., Oxford, 21-53. http://dx.doi.org/10.1016/B978-0-323-22805-3.00003-7

[2] Smith, V., Magalhaes, S. and Schneider, S. (2013) The Role of PVC Additives in the Potential Formation of NAPLs. AMEC Report AMEC/PPE/2834/001.

[3] Starnes, W.H. (2002) Structural and Mechanistic Aspects of the Thermal Degradation of Poly(Vinyl Chloride). Progress in Polymer Science, 27, 2133-2170. http://dx.doi.org/10.1016/S0079-6700(02)00063-1

[4] Tahira, B.E., Khan, M.I., Saeed, R. and Akhwan, S. (2014) Thermal Degradation and Stabilization of Poly(Vinyl Chloride): A Review. International Journal of Research (IJR), 1, 732-750.

[5] Raqueza, J.M., Deleglise, M., Lacrampea, M.F. and Krawczak, P. (2010) Thermosetting (Bio)materials Derived from Renewable Resources: A Critical Review. Progress in Polymer Science, 35, 487-509. http://dx.doi.org/10.1016/j.progpolymsci.2010.01.001

[6] Kaplan, D.L. (1998) Biopolymers from Renewable Resources. Springer, Berlin. http://dx.doi.org/10.1007/978-3-662-03680-8

[7] Benyahya, S., Aouf, C., Caillol, S., Boutevin, B., Pascault, J.P. and Fulcrand, H. (2014) Functionalized Green Tea Tannins as Phenolic Prepolymers for Bio-Based Epoxy Resins. Industrial Crops and Products, 53, 296-307. http://dx.doi.org/10.1016/j.indcrop.2013.12.045

[8] Basso, M.C., Li, X.J., Fierro, V., Pizzi, A., Giovando, S. and Celzard, A. (2011) Green, Formaldehyde-Free Foams for Thermal Insulation. Advanced Materials Letters, 2, 378-382. http://dx.doi.org/10.5185/amlett.2011.4254

[9] Ramires, E.C. and Frollini, E. (2012) Tannin Phenolic Resin: Synthesis, Characterization, and Application as Matrix in Bio Based Composites Reinforced with Sisal Fibers. Composites Part B: Engineering, 43, 2851-2860. http://dx.doi.org/10.1016/j.compositesb.2012.04.049

[10] Anelise, S.N.F., Carla, R.F.V., Matheus, S., Claudia, A.L.C., Maria do, C.V. and Zefa, V.P. (2014) Evaluation of Antioxidant Activity, Total Flavonoids, Tannins and Phenolic Compounds in Psychotria Leaf Extracts. Antioxidants, 3, 745-757. http://dx.doi.org/10.3390/antiox3040745

[11] Gunawan, G., Bourdo, S., Saini, V., Biris, A.S. and Viswanathan, T. (2011) Novel Microwave-Assisted Synthesis of Nickel/Carbon (Ni/C) Nanocomposite with Tannin as the Carbon Source. Journal of Wood Chemistry and Technology, 31, 345-356. http://dx.doi.org/10.1080/02773813.2011.562339

[12] Shnawa, H.A., Khalaf, M.N., Jahani, Y. and Taobi, A.A.H. (2015) Efficient Thermal Stabilization of Polyvinyl Chloride with Tannin-Ca Complex as Bio Based Thermal Stabilizer. Materials Sciences and Applications, 6, 360-372. http://dx.doi.org/10.4236/msa.2015.65042

[13] Zhang, S.J., Lin, Y.M., Zhou, H.C., Wei, S.D., Lin, G.H. and Ye, G.F. (2010) Antioxidant Tannins from Stem Bark and Fine Root of Casuarina equisetifolia. Molecules, 15, 5658-5670. http://dx.doi.org/10.3390/molecules15085658

[14] Fruto, P., Hervas, G., Giraldez, F.J. and Mantecon, A.R. (2004) Tannins and Ruminant Nutrition: Review. Spanish Journal of Agricultural Research, 2, 191-202. http://dx.doi.org/10.5424/sjar/2004022-73

[15] Samper, M.D., Fages, E., Fenollar, O., Boronat, T. and Balart, R. (2013) The Potential of Flavonoids as Natural Antioxidants and UV Light Stabilizers for Polypropylene. Journal of Applied Polymer Science, 129, 1707-1716. http://dx.doi.org/10.1002/app.38871

[16] Grigsby, W.J., Bridson, J.H., Lomas, C. and Frey, H. (2014) Evaluating Modified Tannin Esters as Functional Addi- 
tives in Polypropylene and Biodegradable Aliphatic Polyester. Macromolecular Materials and Engineering, 299, 12511258. http://dx.doi.org/10.1002/mame.201400051

[17] Wetton, R.E., Marsh, R.D.L. and Van-de-Velde, J.G. (1991) Theory and Application of Dynamic Mechanical Thermal Analysis. Thermochimica Acta, 175, 1-11. http://dx.doi.org/10.1016/0040-6031(91)80240-J

[18] Menard, K.P. (1999) Dynamic Mechanical Analysis: A Practical Introduction. CRC Press LLC, New York. http://dx.doi.org/10.1201/9781420049183

[19] Owen, E.D. (1984) Degradation and Stabilization of PVC. Elsevier Applied Science Publishers Ltd., London and New York. http://dx.doi.org/10.1007/978-94-009-5618-6

[20] Luo, Z. and Jiang, J. (2010) Molecular Dynamics and Dissipative Particle Dynamics Simulations for the Miscibility of Poly(Ethylene Oxide)/Poly(Vinyl Chloride) Blends. Polymer, 51, 291-299. http://dx.doi.org/10.1016/j.polymer.2009.11.024

[21] Measuring Mixers for Material Research and Quality Control. Brabender ${ }^{\circledR}$ GmbH \& Co. KG, Brabender ${ }^{\circledR}$ Agencies $^{\circ}$ All over the World, 2012. www.brabender.com

[22] Dynamic Mechanical Analysis (DMA). A Beginner’s Guide. PerkinElmer, Inc., 2008-2013. www.perkinelmer.com

[23] Kim, S. and Kim, H.-J. (2003) Curing Behavior and Viscoelastic Properties of Pine and Wattle Tannin-Based Adhesives Studied by Dynamic Mechanical Thermal Analysis and FT-IR-ATR Spectroscopy. Journal of Adhesion Science and Technology, 17, 1369-1383. http://dx.doi.org/10.1163/156856103769172797

[24] Van Melick, H.G.H., Govaert, L.E. and Meijer, H.E.H. (2003) On the Origin of Strain Hardening in Glassy Polymers. Polymer, 44, 2493-2502. http://dx.doi.org/10.1016/S0032-3861(03)00112-5

[25] Margolis, J.M. (2006) Engineering Plastics Handbook. McGraw-Hill Companies, Inc., New York.

\section{Graphical Abstract}
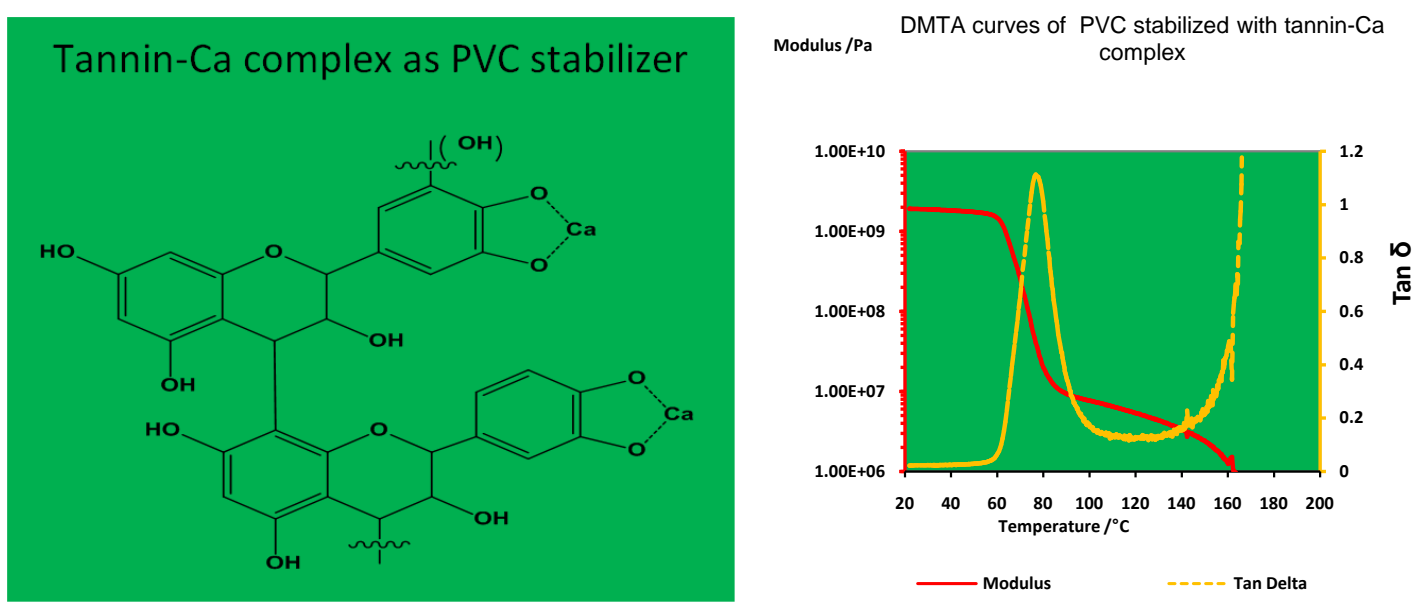